\title{
The Study on Research and Development Decision Process of Fashion Small and Medium-sized Enterprises
}

\author{
Yanwen RUAN \\ Fashion Art. Design Institute \\ Donghua University \\ Shanghai, China \\ e-mail: ruanyanwen.elsa@hotmail.com
}

\author{
Wen GU* \\ Fashion Art. Design Institute \\ Donghua University \\ Shanghai, China \\ e-mail: guwen@dhu.edu.cn
}

\author{
Liwen GU \\ College of Textile \\ North Carolina State University \\ Raleigh, USA \\ e-mail: Lgu2@ncsu.edu \\ Xiaogang LIU \\ Fashion Art. Design Institute \\ Donghua University \\ Shanghai, China \\ e-mail: liuxg@dhu.edu.cn
}

\begin{abstract}
Development and research of new products in fashion small and medium-sized enterprises often lacks of standard. Disarrangement of the developing decision process has the negative effect on their growth and marketing performance. In order to offering a reference decision making standard for them, a cross module decision managing process model is established. It is structured based on the new product developing business process, and also based on the interviews on twelve fashion small and medium-sized enterprises. Besides the model, three main research results are also obtained as following. Four decision modules are extracted. Important decision points are refined. And decision process with information flow and sequence flow is clarified.
\end{abstract}

Keywords-fashion; small and medium-sized enterprises; research and development; cross module; decision process

\section{INTRODUCTION}

Fashion small and medium-sized enterprises (SME) are the important developing force of apparel industry. Past studies have documented that the efficient use of design and designers will take the positive affect on the business performance and competitiveness of SME [1]. As the small size, the relatively low rates of introduction of new products make it difficult to cover the fixed costs [2]. So, the ability of research and development (R\&D) of SME should be improved, and the process of the product decision should be well managed. To clarify the process of product $R \& D$ business and the process of product decision, will assist the decision makers to work efficiently, such as arranging the R\&D project and controlling its cost.

The organization structure of SME often in their initial stage, it leads to the un-objective $\mathrm{R} \& \mathrm{D}$ and decision process. They often lack of standard, and their decision process is usually disarranged. So their final products will take the risk of missing the needs of consumer, unmatching the brand position, lacking of production feasibility [3]. All situations above will affect the growth of SME and negatively influence their marketing performance. In order to offering the reference for SME to make decision more clarify, a R\&D decision managing process is performed for SME in fashion industry. The study is based on the literature review and the former research of $\mathrm{R} \& \mathrm{D}$ business process of apparel SME.

\section{LITERATURE REVIEW}

\section{A. Business Process}

For industrial companies, new product $\mathrm{R} \& \mathrm{D}$ process is a structured sequence flow. The flow follows the activity stream and information stream [4]. They can be summarized as three stages, the formation of theme, the solution of problems, and the realization of products [5]. They can be further divided into the analyzing of demand, the analyzing of problem, the definition of problem, the design of theme, the expression of theme, the selection of schemes, the solution of problems, the design of details, the drawing of sketch, and the realization of product. In the flow above, every stage of R\&D should be followed by judgment and decision, to ensure whether the stage is complete.

The $\mathrm{R} \& \mathrm{D}$ business process in the apparel industry, however, usually can be divided into two types, serial business flow and parallel business flow.

For the serial business flow, it is usually divided into the forecast of developing, the series planning, the formulation of concept, the detailing design and development [6]. Among these stages, the series planning stage includes the selecting of schemes and the market testing of product [7]. Most of the fashion companies take the R\&D managing method based on serial business flow. In the process of the series flow, individual R\&D business stages can be practiced sequentially. Thereby forming the clearly and logically business process [8]. It will be more useful to solve the simple problem, however, the complex product and R\&D process cannot use it. Because it is slow in reacting for the error in the operating process. 
As for the parallel business flow, it originates from Concurrent Engineering (CE). It is a systematic method that concurrent design product and its relative process [9]. For the parallel business operating process of fashion product $R \& D$, every $R \& D$ relative factors should be concerned in it. During the process, enterprise resources should be sufficiently used. The process aims to shorten the development cycle of new product and to reduce its cost. For fashion companies, parallel business flow should synthesize value flow, information flow and object flow. And it can made the series flow into several small cycles, such as theme design, detail design, design review. Through rational distribution of design schedule and time, make the R\&D employees in separated sections start the work of new product development in an integral process as early as possible.

\section{B. Decision Process}

Product developing decision is a process to solve relevant problem for creating a new product [10]. And it also is the process to review and select schemes [11]. Decision process is the arrangement and realization of every stage in the whole process [12]. Furthermore, developing decision process can be divided into inner-module developing decision [13] and cross-module developing decision. Between them, crossmodule decision is more complicate, and it takes the guiding role in the integral decision process for decision makers.

Cross-module developing decision process refers to business decision process based on the series of business module in the process of R\&D. Although many differences in different companies or in different period of product developing, the problems and tasks is almost same that they should make decision [14]. Some researchers also recommend that product developing process is an evolution series of decision unit. Four stages are included, which are initial investigating, information review, developing and testing. All stages are stacking with flow, and the fusion decision points are existed in the stages [15]. For fashion companies, cross-module developing decision process refers to a process combination of different decision tasks in different modules during new product R\&D in one season. Cross-module developing decision for fashion SME is structured in the study based on the developing business process.

\section{InVESTIGATION ON DECISION Process}

Forming decision process is based on the previous study of business process of fashion SME. Selecting the decision points from the mixed business points, furthermore, summarizing the common ground of fashion SME. The research object of former study on business process is divided into three types of fashion SME, they are designer oriented SME, commercial and public oriented SME and original design manufacturer (ODM) oriented SME. The common business process of fashion SME is generalized by the investigating of twelve SME, four for every type, in apparel industry. The common business process is summarized as below [16].

Information collection is the first stage, theme design and product planning are the following ones. Some SME take different sequence order on these two stages, while others will practice them at the same time. In any case, they are considered as the indispensable parts in the developing process. The design and development direction of new products are determined in above process. After that, the stage of detailed design is applied. Designers should finish the design content of technic, fabric, color, style as well as the technical Bill of Material (BOM). All these content should be submitted to review. Different fashion SME often give different evaluation standard. Through evaluation, the content will be selected, then, product developing process is following. After the stage of developing and making samples, all the samples should be reviewed. The final ones are sealed at last. As the common business developing process shown above, the study brings forward problems to solve.

- Extract decision module from the common developing business process.

- Refining the important decision point from the business process.

- Clarifying the decision process through the connection of information flow and sequence flow.

\section{A. Method}

Twelve companies of three different types of fashion SME are selected for investigating. Four for each type are interviewed. For the purpose of this research, the classification standard in industrial, retail and wholesale industries in China will be used. It defines SME that employ fewer than 1000 employees and have an annual turnover lower than 400 million RMB [17].

Chief designers are interviewed. As agreements with them, the name of companies cannot be public. While with the permission, the process of interviewing can be recorded.

The interview brief is about garments design detail and potential design decision points that are occurred during the process of new product design. The question brief with eight questions is reviewed by five experts in fashion field, and five questions remained at last as final interview brief, after deleting and modifying the inappropriate questions.

\section{B. Four Decision Modules}

From the common developing business process, there are four main business stages that are practiced by most of the fashion SME. Based on the literature review, they can be generalized into four main decision modules, theme planning decision (TPD) module, product planning decision (PPD) module, product design decision (PDD) module, sample development decision (SDD) module.

TPD refers to the choice in the product conceptual design and merchandising process of new season. It is one of the leader modules. It includes the design direction of color, silhouette, fabric and detail, as well as the story of theme inspiration.

PPD refers to the choice in the process of new season product matching from the perspective of sales and production. It is carried out with TPD at the same time or before TPD. Both of them are the leader modules of new product developing decision. PPD includes the matching of 
category, color, sales volume and the planning of price, cost, return, progress rate.

PDD refers to the choice related to the specific product design. It is the operation process module to carry out the content in TPD and PPD. It includes sketch drawing, material choosing, color choosing, style designing, detail designing, BOM making.

SDD refers to the choice in the process of sample testing and making. And it is the section to transfer the new season product from theme into entity. It includes local-sample development decision making, sample garment development decision making, sample garment review decision making. The decision of pattern developing, technic developing, and trial-production are included in the module.

The cross module decision process model of fashion SME is established in the study, and is developing businessoriented. The normalization of product development is expected to be improved in each section of R\&D decision workflow through clarifying each decision key point involved in development process. The model is structured by using the method of BPMN2.0 (Business Process Modeling Notation 2.0) which published by Object Management Group (OMG) in 2011, and the description of notation is shown in below table [18].

TABLE I. NOTATION DESCRIPTION OF BPMN

\begin{tabular}{|c|c|c|}
\hline Notation & Graphic & Description \\
\hline Task & & $\begin{array}{l}\text { A task is a unit of work-the job to } \\
\text { be performed. It is an atomic } \\
\text { activity within a process flow }\end{array}$ \\
\hline $\begin{array}{l}\text { Collapsed } \\
\text { Subprocess }\end{array}$ & & $\begin{array}{l}\text { A collapsed subprocess is a } \\
\text { decomposable activity. It can be } \\
\text { linked to another process diagram }\end{array}$ \\
\hline Group & $i_{-}^{-}$ & $\begin{array}{l}\text { An arbitrary set of objects can be } \\
\text { defined as a Group to show that } \\
\text { they logically belong together }\end{array}$ \\
\hline Start Event & & $\begin{array}{l}\text { Untyped start event that triggers a } \\
\text { new process instance }\end{array}$ \\
\hline End Event & & $\begin{array}{l}\text { The untyped end event typically } \\
\text { marks the standard end of a process. }\end{array}$ \\
\hline Information Flow & & $\begin{array}{l}\text { A data object can be read at the start } \\
\text { of an activity or written upon } \\
\text { completion. }\end{array}$ \\
\hline Sequence Flow & & $\begin{array}{l}\text { Sequence flow defines the } \\
\text { execution order of activities. }\end{array}$ \\
\hline Data Input & & Data Input \\
\hline Data Output & & Data Output \\
\hline $\begin{array}{l}\text { Inclusive } \\
\text { Gateway }\end{array}$ & & $\begin{array}{l}\text { When splitting, one or more } \\
\text { branches are activated based on } \\
\text { branching conditions. When } \\
\text { merging, it awaits all active } \\
\text { incoming branches to complete. }\end{array}$ \\
\hline $\begin{array}{l}\text { Event-based } \\
\text { Gateway }\end{array}$ & & $\begin{array}{l}\text { Is always followed by catching } \\
\text { events or receiving tasks. Sequence } \\
\text { flow is routed to the subsequent } \\
\text { event/task which happens first. }\end{array}$ \\
\hline $\begin{array}{l}\text { Exclusive } \\
\text { Gateway }\end{array}$ & & $\begin{array}{l}\text { Both Exclusive and Event- Based } \\
\text { perform exclusive decisions and } \\
\text { merging Exclusive can be shown } \\
\text { with or without the "X" marker. }\end{array}$ \\
\hline
\end{tabular}

\section{Developing Decision Process of SME}

\section{A. Theme Planning Decision Module and Product Planning Decision Module}

As is shown in Fig.1, theme planning decision (TPD) module and product planning decision (PPD) module are carried out simultaneously. Both of them are the lead modules of the PDD process for a product collection in the new season.

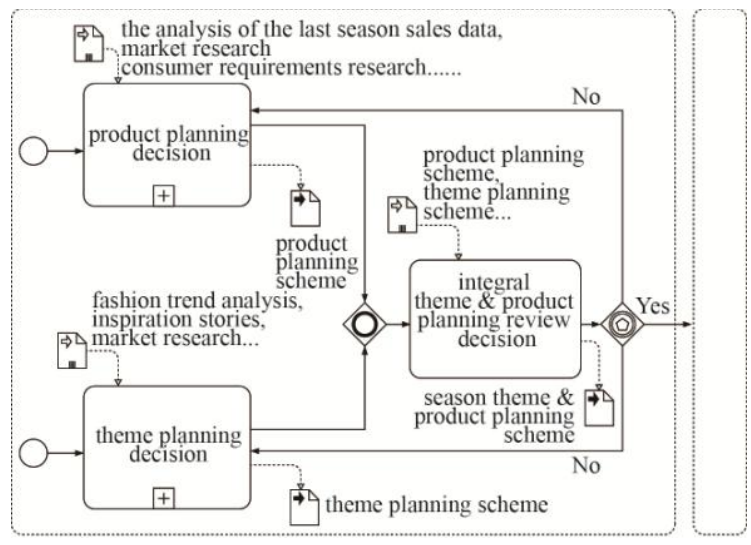

Figure 1. Decision process in TPD and PPD.

In order to create multiple alternative schemes of TPD, as is shown in Fig.2, information of fashion trend analysis, inspiration stories, market research etc. is imported in the TPD module. As a result, a particular chosen scheme will be outputted from the TPD module.

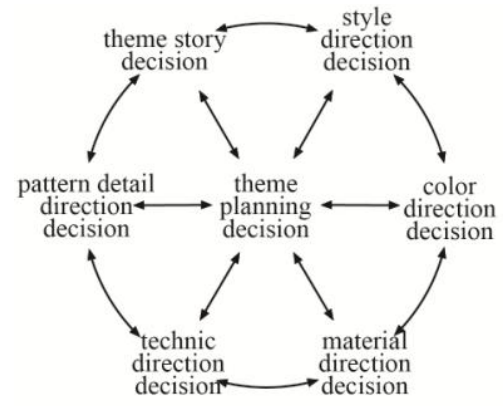

Figure 2. Theme planning decision section.

During the process of PPD, as is shown in Fig. 3, related information of the analysis of the last season sales data, market research etc. is imported into the PPD module. A selected product planning scheme will be obtain through the module.

The results of these two modules are gathered for an integral review section. Related schemes of theme planning and product planning along with the other information are taken into account during the process. If the schemes can pass the review, PDD module will be activated, otherwise the schemes will be adjusted in the modules of TPD and PDD. Theme and product planning scheme for the new collection will be gained through the integral review section. 


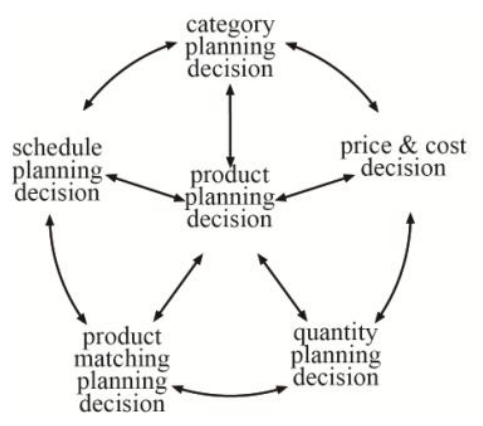

Figure 3. Product planning decision section

\section{B. Product Design Decision Module}

As is shown in Fig. 4, the product design decision (PDD) module contains three decision sections which are product design scheme decision making, design scheme review decision and outsourcing product development decision making.

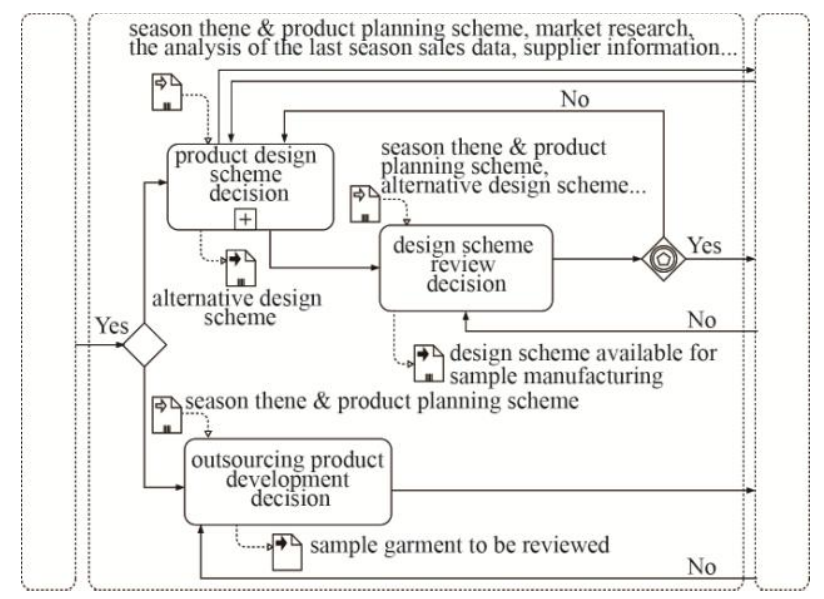

Figure 4. Decision process in PDD

Product design scheme decision section requires the theme and product planning scheme obtained through the last decision section, the analysis of the last season sales data, market research, supplier information etc., which is shown in Fig. 5. A series of alternative product design schemes will be outputted consequently. Meanwhile, these product design schemes are closely relative to the local-sample development decision.

Design scheme review decision section requires all alternative product design scheme, product planning scheme and theme planning scheme for decision maker to review the product design schemes. This section outputs the product design schemes and the BOM which is available for sample development. If the documents of design schemes and BOM can pass the review, SDD will be activated, or the documents will be adjusted in the section of product design scheme decision till they can pass the review.

Outsourcing product development decision section requires sending the theme planning scheme and product planning scheme of the new season to the outsourcing partners. The outsourcing partners carry out the decision on product design scheme creating and sample development. Sample garments are obtained through decision for further review.

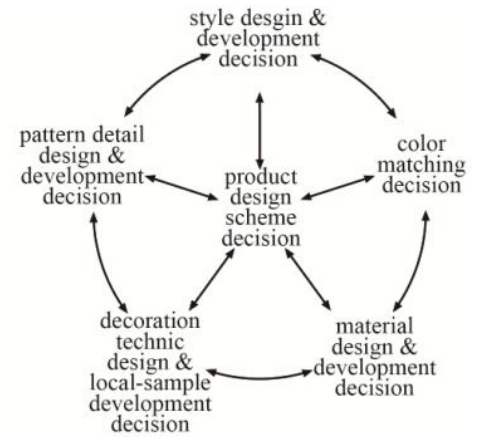

Figure 5. Product design scheme decision section

Outsourcing product development decision section requires sending the theme planning scheme and product planning scheme of the new season to the outsourcing partners. The outsourcing partners carry out the decision on product design scheme creating and sample development. Sample garments are obtained through decision for further review.

\section{Sample development decision module}

As is shown in Fig. 6, Sample development decision (SDD) module contains three sections which are localsample development decision (L-SDD), sample garment development decision and sample garment review decision making.

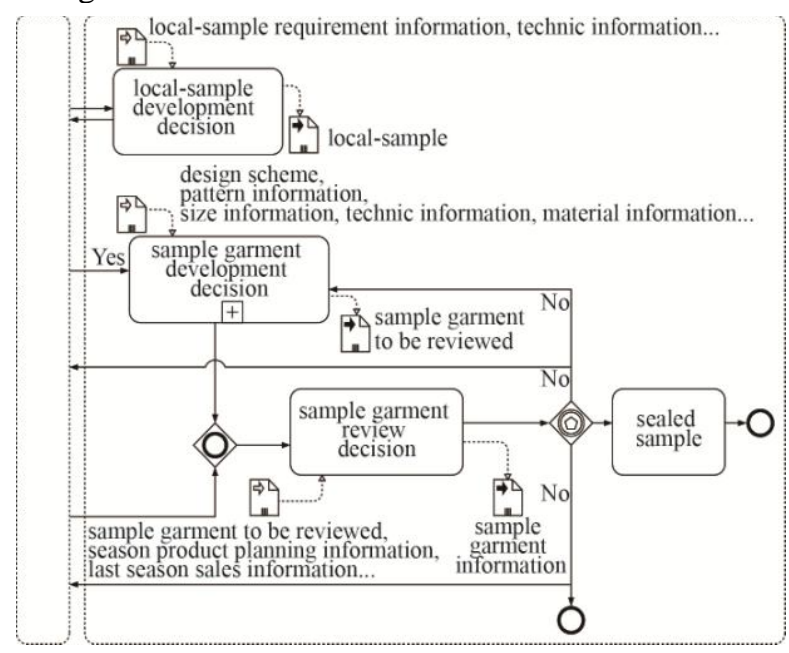

Figure 6. Decision process in SDD

L-SDD section works to react with product design scheme decision section in PDD module. As is shown in Fig. 7 , it requires importing the local-sample requirement information and related technic information. L-SDD information will be outputted from this section and will be imported into the section of product design scheme decision making. Sample garment development decision requires 
importing design scheme, BOM, pattern information, size information, technic information, material information etc. Sample garments to be reviewed are outputted as a result.

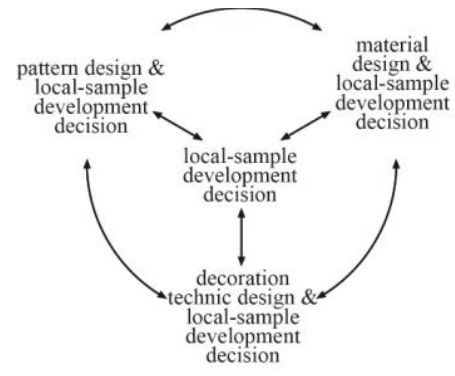

Figure 7. Local-sample developing decision section

The sample garments to be reviewed from the sample garment development decision section and the outsourcing product development decision section are gathered and imported into sample garment review section. As is shown in Fig. 8, this section requires almost all the related information mentioned above such as theme planning scheme etc. The passed sample garments will be sealed while the rejected sample garments will be handled in four optional methods: being returned to outsourcing product development decision section for modification, being returned to product design scheme decision section for modification, being returned to sample garment development decision section for modification, or being canceled.

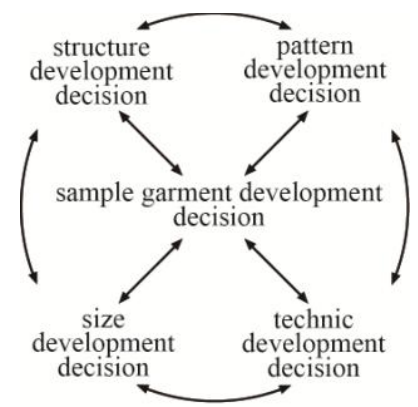

Figure 8. Sample garment development decision section

\section{CONCLUSION}

Three main problems mentioned are solved in the research to establish the fashion SME R\&D decision process model. Firstly, four decision modules are extracted from the common SME R\&D business process. Secondly, through the interviewing, the important decision point has been refined. Thirdly, the decision process module is established by clarifying the decision process with information flow and sequence flow.

To sum up, fashion SME R\&D decision process model reflects the relationship among the decision key points and connects them together. Establishing the model makes the decision sections of the companies more directed. Making clear how the outputted information acts other decision points eliminates the information isolate island phenomenon, and helps decision maker control the new product development in the whole season more comprehensively, which is of great significance in the perspective of improve the accuracy of product development. For the further research, more empirical analyzing and case studies can be practiced with fashion SME to optimize the decision process.

\section{ACKNOWLEDGMENT}

The authors wish to acknowledge the Shanghai Style Fashion Design \& Value Creation Knowledge Service Center (No.ZX201311000031) program.

\section{REFERENCES}

[1] J. Hertenstein,P. Marjorie, and V. Robert, "The Impact of Industrial Design Effectiveness on Corporate Financial Performance," Journal of Product Innovation Management,vol. 22, Jan 1. 2005, pp. 3-21.

[2] M. Bruce, R. Cooper, and D. Vazquez, "Effective design management for small businesses," Design studies,vol. 20, May 31. 1999, pp. 297315.

[3] M. Bruce,S. Potter, and R. Roy, "The Risk and Rewards of Design Investment," Journal of Marketing Management, vol. 11, July 1. 1995, pp. 403-417.

[4] J. Utterback, B. Vedin, E. Alvarez, S. Ekman, S. Sanderson, B. Tether, and R. Verganti, Design-inspired innovation, USA: World Scientific Publishing Co. Pte. Ltd., 2006.

[5] K. Ulrich, S. Eppinger, Product design and development, McGrawHill Higher Education, Jun 5, 2005.

[6] Stone, and J. Samples, Fashion Merchandising: An Introduction. Glencoe/McGraw-Hill School Publishing Company, 1990.

[7] C. L. Regan, D. H. Kincade, and G. Sheldon, "Applicability of The Engineering Design Process Theory in the Apparel Design Process," Clothing and Textile Research Journal, vol. 16, Jan. 1998, pp. 36-46.

[8] U. Pitimaneeyakul, K. Labat, and M. Delong, "Knitwear Product Development Process: A Case Study," Clothing and Textile Research Journal, vol. 22, Jun. 2004, pp. 113-131.

[9] Wang, M. Meng, and J. Huang, "The Study on The Method of Modular Product Family Design Based on Design Structure Matrix," Computer Integrated Manufacturing System, vol. 9, 2003.

[10] H. Simon, G. Dantzig, R. Hogarth, C.Plott, H. Raiffa, T. Schelling, K. Shepsie, R. Thaier, A. Tversky, and S. Winter, "Decision Making and Problem Solving," Interfaces, vol. 17, Oct. 1987, pp. 11-31.

[11] T. Mezher, M. Abdul-Malak, and B. Maarouf, "Embedding Critics in Decision-Making Environments to Reduce Human Errors," Knowledge-Based Systems, vol. 11, Nov. 1998, pp. 229-237.

[12] P. Badke-schaub, and G. Anja, "Patterns of Decisions in Design: Leaps, Loops, Cycles, Sequences and Meta-processes," In DS 31. The 14th International Conference on Engineering Design (ICED 03), Stockholm. 2003.

[13] Y Ruan, L Gu, W Gu, and X Liu, "Design Decision Method for Fashion SME Based on Consumer Behavior", unpublished.

[14] V. Krishnan, and K. Ulrich, "Product Development Decision: A Review of The Literature," Management Science, vol. 47, Jan. 2001, pp. 1-21.

[15] R. Cooper, "Third Generation New Product Processes," Journal of Product Innovation Management, vol. 11, Jan. 1994, pp.3-14.

[16] Y Ruan, L Li, J Zheng, and X Liu, "Analysis on Process of Product R\&D of Apparel SME Brands," unpublished.

[17] Information on: http://www.gov.cn/zwgk/201107/04/content_1898747.htm

[18] B Silver, B Richard, BPMN Method and Style, Aptos: Cody-Cassidy Press, 2009. 